\title{
Entity-Relationship Model of Adult Education in Regional Extended Education System
}

\author{
Vitaly A. Vexler ${ }^{1}$, Ruslan I. Bazhenov ${ }^{1} \&$ Natalia G. Bazhenova ${ }^{1}$ \\ ${ }^{1}$ Sholom-Aleichem Priamursky State University, Russian Federation \\ Correspondence: Vitaly A. Vexler, Shirokaya Street, 70a, Birobidzhan, 679015, Russian Federation. E-mail: \\ vitalv74@mail.ru
}

Received: June 3, 2014 Accepted: July 15, 2014 Online Published: September 28, 2014

doi:10.5539/ass.v10n20p1 URL: http://dx.doi.org/10.5539/ass.v10n20p1

\begin{abstract}
At the present time a system of adult extended education is on the turn of essential changes, caused and involved by radical changes in social and individual conscience, system of public and personal necessities, new approaches to an adult education, levels of advanced training and retraining system modelling. Many regional educational institutions, which put into life advanced educational programs, are starting to understand the necessity of complex approach to content selection of educational material system and advanced education courses holding, switch to new models of education, which take into account demands, which are put forward by market relations and are forming in the region. The aim of this study is bringing to the light the main demands, which are put forward by regional labour market to the content and organization of adult education in advanced education system, and model of adult education content and organization formation, adapted to labour market development. To the main conclusions of the study we may relate the fact that adult training on the information technology basis is rationally to build on the basis of a job description (activity and personality model), qualified characteristics (graduate image) and literary work program, taking into account modern demands in primary computer-based training area. When constructing the content part of adult training on informational technologies, it is necessary to take into account: an adaptation and course correction capability, dependently on the contingent of trainees and the training documentation volume; development of narrative component, which affords listeners to acquire new information technologies, which are most-coveted in the region; correspondence of educational content to activity peculiarities in informational technologies area; capability.
\end{abstract}

Keywords: adult education, pedagogical technologies, modelling, entity-relationship model, regional education

\section{Introduction}

Changed under the influence of new socio-economic environment, educational system sets in front of itself the new challenges, the main idea of which is to make adults possess all the necessary knowledge base and skills, helping them "to survive" nowadays. An activity of adult advanced education system in the region should be directed on adult training in such a way, that subsequently, when they gain a bundle of knowledge, they will be able to provide positive changes, both in professional activity area and their personal interests' area. That is why raises the question according to what pattern, which meets all the necessary demands, the regional system of advanced education will fulfil its education of adult trainees in modern informational environment conditions. This way, a formalized model of specialist, describing all personal and professional characteristics, necessary for successful professional activity acquirement, can be set. On the basis of given pattern it will be necessary to develop the educational model, which reflects content-related (what to study) and organizational (how to study, where to educate, who will educate) components. The problem of efficient adult education modelling is persistent in the world practice: psychophysical peculiarities of adults, getting advanced education are reflected in materials of P. T. von Hippel and J. L. Lynch (2014), concerning modelling of education system for adults generation in Lithuania (Dromantiene \& Zemaitaityte, 2014), adult educational system's peculiarities in Portugal were considered by P. Guimarães, N. Alves, C. Cavaco and M. Marques (2014), experimental researches on adult education of various ethnic, national, cultural layers in Turkey were published by S. S. Gül, H. E. Kaya and A. Schweighofer-Brauer (2013), socio-political aspects and barriers of adult education models were brought out by K. Rubenson (2010), modern reforming of conceptual approaches to generation of working educational programs reported in his articles G. McNamara, P. Joyce and J. O'Hara (2010), questions of theoretical and 
practical prospects of adults' literacy rises L. Tett and R. St. Clair (2010), peculiarities in formation of adult educational model from "Northern Countries" (Finland, Denmark, Norway, Island) allocates A. C. Tuijnman (2003).

\section{Methodology}

Understanding of a term "model" is construed differently. Usually this is some kind of structure, pattern, from which clones can be generated, with this not only direct reproduction, but also modifications with some changing conditions are assumed. The word "model" descended from Latin «modulus», that means "measure, pattern". Globally speaking, model is an abstract term of a standard or a sample of some system.

Although in literature the term "model" is interpreted as some image, an analogue, sample for generation, a scheme of some process or event, happening in nature or society, the model is an almost informative term and it should be treated as visualized or materially implemented system, which is able to replace it when it is reflected or reproduced (Leonelli \& Ankeny, 2013).

In general, the model is a system object, consisting of interconnected components, which fulfil certain functions in its framework, and is generated for determined purpose, and in the process of this goal's reaching it is functioning and developing. For system object management and its behaviour in external environment modelling, information about its own state and external environment is used. The model possesses the following characteristics of a system: continuity and divisibility; stable links availability, organizational framework, and emergency (compositing apportions system with new characteristics) (Wallach et al., 2014).

Models are classified by different types of generalized characteristics (imitational, subject, informative, situational, analogue, mathematical etc.), therewith, models can be static, that reflect original structure or dynamic, that reflect behaviour and functioning of original.

Entity-relationship model is considered in many sciences in psychology, for example, it is understood as a system of signals, arranged by certain rules, which are generated by display media and contain information about a subject-to management (control), eternal environment and control system itself. On the basis of perception of the entity-relationship model an image of real situation shapes into operator's mind (Zhang, 2013).

For entity-relationship modelling it is necessary to pass a number of stages. The process, conducted from "the object of cognition" to "formal construction", is called "formalization", and the reverse process is "an interpretation", which is frequently used in the World learning and education. Formalization as a substitute to a real object or the process of its formal description is a process of entity-relationship modelling. Any system modelling is impossible without preliminary formalization. Forming entity-relationship model, a man uses it instead of the object-original to learn characteristics of this object, its behaviour forecasting.

This way, in our understanding a model is a system of elements, visualized or materially accomplishable, which reflects a subject of research and is capable to replace it the way that its examination gives us new information about the object.

When we are modelling, we, inherently, create the analogue of objective reality. Modelling is one of the main categories of cognitive theory: essentially, the idea of modelling is the basis of any method of scientific research as theoretical (with which various sign and abstract models are used) and experimental as well (with subject model usage) (Bridewell, 2006).

Recent years modelling found its wide usage not only in the science, but in education as well, in conditions of efficient professional training search. Modelling supposes an entity of psycho-pedagogical purposes, defining special set of forms, methods, approaches, procedures, that means all organizational and methodological tools, directed to realization of the goal desired.

Under the modelling process of education in the system of adult advanced education we mean planning of the educational process, which reflects state and regional customer order (curriculum and work programs arrangement, which correspond demands of state educational standard) and composition analysis of the educational process.

Educational model should meet the market environment and be based on the following principles: human priorities, economic efficiency and sociomorphy.

The principle of human priorities appears from general pedagogical principles of natural conformity and humanization, which tells about abeyance the real necessities, interests and opportunities of trainees, which represent an opportunity of initiative and improvisation of the educational process participants. Self-development principle means creation of its dynamic, flexible and able to changes reconstruction or simplification on the way 
to realization. Systemic principle tells that created model should represent itself an open system with complete structuring, functioning mechanism and inner modification methods. Continuity principle is based on systemic principle, of which follows and interdependence of subsystems' functioning, which provides a possibility of continuous passage from one component to another. Economic efficiency principle provides necessity of enterprises and organizations satisfaction in personnel of necessary amount and adequate professional qualifications, due-by-date with ensured result and optimal resources' provision. Sociomorphy principle provides an adequate correspondence to the society development demands with taking into account the history of its development, traditions, and socio-genetic mechanisms.

The model of adults' education, which is being designed, should have, at least, three blocks: learning environment, educational process; job placement and adaptation of specialist. General characteristics of learning environment come down, first of all, to educational institution characteristics, where specialists of given profile are trained, however, apart from them, some political and socio-economic factors, having determinative influence at the character of society's development in general, should be taken into account. The educational process is characterized by specific communication form of all educational environment elements. Factors, determining job placement and specialist's adaptation process, are starting to form in the process of education. This is accomplished by means of information acquisition about a character of specialist's main functions (theoretical component), certain working skills' transfer by means of business games carrying out, practice organizing (practical component), and due to part-time employment, which may take place in the process of education (preliminary job placement and adaptation).

The following scheme of educational modelling is offered:

Knowledge and skills area (disciplines);

Demands to qualitative composition of teachers;

Forms and specificity of lessons and practical work carrying out;

Material and technological conditions of education;

We consider, that educational model includes:

Model of the in place "ready" specialist, which contains: a) specialist's activity model (in which aims, problems, actions and operations are highlighted); b) specialist's personality model (in which professionally important qualities are separated);

\subsection{Specialist's Training Model}

Under specialist we understand professionally competent employee, possessing necessary for qualified and productive work accomplishment by means of knowledge, skills, qualities, experience and individual activity style.

Educational quality depends on, coherence, of three main moments: aim of education (for which purpose to study), content of education (what to teach) and principles of educational process organization (how to teach). Model of specialist is reflected in educational aims, containing in itself common task system and a system of skills, adequate to them (occupations). A basic educational objective contains in a problem of positive, creative human personality forming, which is capable to adapt to production changes, capable to continual study and qualification updating.

Model of specialist reflects demands to personal qualities of future specialists; their professional qualities and efficiency; knowledge, efficiency and skills on different academics; physical and psychological state characteristics etc. Model consists of subject and semantic parts. Subject model, essentially, is a customary to everybody program of delivered course. It goes up on a very subject principle, sections and topics to be studied are listed there. Semantic model represents itself content of subject area on this or that knowledge level. The model contains relational order of priority and logical connections matrixes, study sequence of subject area objects, graphic representation of logical connections.

Entity-relationship model of specialist, essentially, is a model-image of profession. Educational model becomes a superstructure over entity-relationship model of specialist, making the latest its component. If entity-relationship model of specialist answers the question about the kind of knowledge, efficiency, skills and personal peculiarities should the specialist possess, the model of specialist training answers the question: how to achieve this?

Three components should be foreseen in the model of specialist: 
Types of activity, determined by peculiarities of our age (such abilities and knowledge, which are necessary not only for present specialist, but for the representatives of other specializations, for example: ability to study, collective management ability, and readiness for collective activity);

Kinds of activity, oriented on professional demands, specializations (for each profession there is determined its own, concrete set of skills and abilities);

Types of activity, determined by socio-political system of country, its mental and moral system (personality block includes moral and world vision problems, public culture demands).

Technical process of specialist model forming includes a number of stages:

Professional situations bank creation;

System of roles and occupations defining;

Knowledge, proficiency, skill basis working-out;

Personal peculiarities defining, necessary for proficient fulfilment of concrete types of professional activity.

Model objective is achievement of a listener competence and mobility on the basis of the process of personal and professional mind-sets changing.

Thus, as a purpose of specialist training there serves a man, possessing not only the determined properties, the man-achiever (society order), but the "man with self-reflection, changeability, evolution capability-the man of possibilities, ready to become "acme"-professional", who achieves the highest level of self-realization as an activity subject.

Specialist model is necessary to be considered in two aspects-a profession and a profession bearer models, which are the models of educational institute graduate. If to consider the educational model as an integral procedure, it is necessary to determine an input and output parameters:

Input parameter-is a grown-up, which needs knowledge under the influence of many reasons. This is "a knowledge consumer"-courses listener, entrant;

Output parameter-is a graduate, formed in accordance to present model and who completed professional competence expertise.

Under professional competence of a graduate we understand his readiness and ability to accomplish determined specialized functions and solve professional problems in coherence with norms and standards.

A qualification level estimate is represented by its professional competence expertise, supposing qualification test, examinations, and total and staged competency test, psyhodiagnostics holding, with the aim to determine correspondence to model demands. In order to help in complex estimation of educational quality giving, there may be used the ultimate consumers of educational services-graduates of educational courses and employers.

Knowledge requestor should possess the following row of criteria, which afford him to complete training. They may include: level of knowledge; psychophysical abilities (inborn and acquired in the root of previous professional and educational activity abilities, personal qualities, proclivities and motivations); necessity in motivation.

Necessities are the feeling of shortage in something and on its basis, conation to something. Particular necessities are based on the aim of reserving or acquisition of working space and personal interests. Social necessities include federal responsibility on the basis of constitutional and legal statutory documentations, which answer expectations of various social groups. Production requirements are based on procurement of regional undertakings by competent personnel.

Motives, that are something, which immediately motivates people to actions, are formed on the basis of necessities and the estimate of their satisfaction possibility. A motive acknowledgement supposes that a person not only sets his heart to something, but also sees, at least, the ways of his goals achievement. Achievements motivation is a connation to results improvement, dissatisfaction with the scored, insistence in his goals pursuing, connation of objects at all accounts gaining is one of the main personality peculiarities, which influence the whole human life (Bipp \& Dam, 2014).

Talking about motivation in respect to adult education, it is necessary to notice few important aspects, so as adults' motivation in root differs from children's and teenagers' ones. Grownups start their education fully understanding its necessity for the following objectives (Gegenfurtner \& Vauras, 2012): 
New knowledge, know-how attaining, which widens professional abilities of specialist, makes higher his being in demand and irreplaceability on present day production tasks that means, his proficiency growth in the eyes of colleges and employers.

Specialist advanced training, who becomes more solicited, enhances the authority of worker in the company that, absolutely, promotes career development.

An important motivation peculiarity may be considered the worker's longing to raise his salary after passing the retraining or refresh courses.

New skill development and acquirement of new knowledge enhances chances to be more desired on the labour market.

Personal enrichment and the interest in fresh information receiving, concerning favourite and interesting topics.

Thus, the peculiarity of adult educational process planning may be considered the fact, that a grownup, who possesses all the necessary qualities (self-conscience level, life experience, a certain level of advances, responsible attitude to its activity), which assist an active participation of the grownup himself at all stages of educational process (Desjardins, 2010).

Educational model receives into itself profession and graduate images, reflects personal qualities and professional qualification demands, determined this century peculiarities, regional market demands, specialization demands, socio-political state structure and includes the following components: system of common task and adequate to them abilities; personal peculiarities, necessary for activity accomplishment; developed educational programme and professional competence expertise.

Regional aspect of our research is determined by the link between the educational process with economic and social necessities of the territory of the man's residence. In modern dictionaries the term "region" is interpreted in different ways. We adhere to the following definition: Region is a part of a country, representing itself an entire socio-economic system, possessing economic, political and sentience, general historical bygones, cultural and social peculiarities. Research of regional labour market, consideration of regional economic space and regional institutes' development tendencies afford to create the basis of the informative base of educational space.

Thus, in process of educational modelling, we should take into account the following aspects:

Regional labour market analysis, because in the process of analysing of employers request on specialist's demand, we form demands to the model;

Future forecast, that affords to take into account demands for the profession changing and its nearest development area;

Educational institute possibilities, because it is important to consider possessing necessary technical base, pedagogical personnel and reliance of advanced educational technologies;

External environment factors: economic, political, social, demographic, cultural, technological;

Andragogical educational principles (educational peculiarities consideration of adult education).

Under the influence of this factors a set of knowledge, abilities and skills is formed, minute description of all intellectually-professional and socio-psychological qualities of specialist, educational program is projected and new educational module is created.

Let us consider given system of factors more comprehensively:

\subsection{First Factor of Influence: Regional Labour Market Analysis}

Under the labour market we consider economic relation system, concerning purchases and sells of labour power, where supply and demand and prices for it are shaped. Three main labour subjects interact in the labour market:

Enterprises, searching for specialist;

Specialists, searching for job; among these are graduated diplomats, applicants, searching for other job (more well-paid probably) and unemployed citizens;

Educational institutes, training specialists, in accordance with market necessities.

A product on the labour market is a complex of knowledge, abilities and skills of a specialist, searching for a job. A dynamic of relationship of these three subjects forms the labour market (Green, 2009). 
Necessities in specialists on the labour market can be simulated, analysed and forecasted by process dynamics description of "cooperation of three informational and analytical models":

vacancy model (necessity of an employer);

specialist model (proposal of labour market);

educational service model (educational system proposal).

new developments survey in various areas of informational technologies (Weiler, 2005).

\subsection{Second Factor of Influence: Forecast for Future}

Education, should be "principally prognostic", taking in to account development tendencies of one or another brunches, factor dynamics and scientific knowledge in general, creeping scientific and technological discoveries and prospects of their usage in future". Creative problem of forming and in-time outstrip correction of advanced professional education claims "prognostic professional models of specialists", reliable outstrip informational procurement, giving an opportunity of "conjoin" forecasts of scientific-technical researches with pedagogical and didactic forecasts.

\subsection{The Third Factor of Influence: Educational Institute Capabilities}

Educational institute, implementing the program, should possess material and technical base, corresponding to the acting sanitary-technical norms and providing training realization of all kinds of listeners carrying out, provided by curriculum.

For educational institute the following aspects are essential:

Human resources and their qualification;

Material and technical potential, first of all, characterizes such educational conditions as educational areas provision, educational laboratory equipment, computer equipment etc.;

Technological potential is a usage of modern educational technologies and means and know-how.

\subsection{The Fourth Factor of Influence: External Environment Factors}

An important attribute of educational system as an open system is external environment availability and multidimensional connections with it. An external environment can be as associate of educational system in its searching of development and the factor, limiting it as well, but anyway, it is a factor of straight influence on the shaped educational space.

Social factors reflect social stability level in society, social structure, social safety and criminogenic situation. Content of social factors includes:

Social culture (accomplishment, educational norms and values system, social set of mind and its cultural development, regional and national peculiarities);

Demographic and migration factors influence contingent and listener's quantity and its cultural development, regional and national peculiarities);

Social structures (social groups, their development tendencies, typical family structure).

Economic and technological factors reflect state and peculiarities of economic and technological development of state and region, working process transformation, management concept, organization forms of enterprises and institutes and population welfare level. Population's paying capacity increase provides facilities for advanced educational services development.

Political factors are defined by state of internal and external policy, define regulatory framework of educational institute activity and qualification demands to specialization.

Natural factors reflect climatic and ecological elements of influence on specialization model formation.

Fifth influence factor: andragogical educational principles. Distinctions of adult students from school students were comprehended little by little by science, a special didactics' chapter, named "andragogy", in which there come to the light and are developed the principles of adult education.

Andragogical learning principles are based on the following main theses: adult life experience-one of the sources of his education; adult plays a leading role in his development; learning is constructed as a joint activity of teachers, students and his colleagues in professional activities. Therefore, when designing, a training module must adhere to the following basic provisions (Merriam, 2010): 
A leading role in educational process belongs to an adult himself (because he is a student, but not a learner):

Translational educational methods excluding, when the aim, the problem, and the content of education depend only on a teacher;

A student goes for self-realization, independence, autonomy and acknowledges him to be so;

A student possesses life experience (everyday, social and professional) experience, which can be used as an important source of education for himself and his colleagues;

A student recons upon the urgent appliance of achieved in the course of education abilities, skills, knowledge and qualities;

An adult is educated to solve an important life problem and to achieve a concrete aim;

An adult student raises the bar concerning quality and results of the education.

Education is set in the process of cooperation activity of students (listeners) with tutor (a teacher);

A teacher, which educates adult students, should possess the following qualities: patience, in-touch capabilities, sympathy, benevolence, organizational skills, accuracy, self-criticism and other;

Educational process is determined essentially by temporal, space, every day, professional, social factors, which either restrain or assist it.

The main pedagogical provisions consist in that the leading part in educational process is played by a student. Student's function, in this case, is in helping the student in revelation, systematization, formalization of personal experience of the last, correction and his knowledge acquisition. Andragogy in spite of lecture preliminary provides practical problems, practical studies, often of experimental character, discussions, business games, concrete production tasks and problem solving (Beckett, 2010).

In the process of education, the positive results are brought by project method. In his basis there is a development of cognitive, creative skills; abilities in constructing own knowledge, orientation in information space skills, critical thinking development. Results of fulfilled projects should be, as the saying goes, "perceivable", that is, if it is theoretical problem, its concrete solving, if practical-a concrete result, ready for implementing.

In the basis of creative projects lie research methods of education. An entire activity of adult listeners is concentrated on the following stages: problem defining and the problems, following from it; their solving hypothesizing; research methods discussion; data acceptance carrying out; data analysis; final results execution; summarizing, correcting (Hava \& Erturgut, 2010).

Thus, the factors, mentioned by us, influence the model of specialist education; form its scientific, social and economic tendency. Under the influence of these factors, there is formed a set of knowledge, abilities, and skills, detailed description of all intellectual and professional and socio-psychological qualities of specialist, educational program is designed and educational module is created, which includes ready logarithm of teaching situation. One of the main components of educational model of adults in advanced education becomes regional component. In its basis lies the analysis of state and perspectives of socio-economical regional development, defining this list of currents and specializations, according to which it is necessary to fulfil advanced training of specialists. Regional component represents a row of normative demands to the educational content and quality and should have an outstrip character, represented in regional development tendencies.

\section{Results}

Educational content should consider reflecting in it of two sides of readiness for professional activity; functional (activity model) and professionally important qualities (personality model).

Description of specialist's activity kinds (professional problems) may be grouped on the basis of reconstructed in accordance with the new social conditions three-blocks model on the following basis: 1) kinds of activity, corresponding civilization and common cultural norms of specialist of corresponding level; 2) moral and world vision problems, connected with national, native, cultural identity and personal self-identification; 3) kinds of activity, specific for given profession.

Specialist personality model defines necessary qualities and properties, knowledge, abilities and peculiarities, necessary for successful line of work acquirement. A personality model, projected by us, is maximally oriented on personal qualities forming, which are the heart of informational competence, such as systemic thinking, practical creative abilities and a skill of independent own knowledge constructing. Without these qualities an 
efficiency of professional activity in professions like "human-technique" decreases significantly and sometimes leads to the loss of imposed on a specialist functions.

Activity and personality models lay in the basis of job analysis building. Job analysis is a document, regulating requirements building technology, which are imposed by profession to personal qualities, psychological capacities, and psycho-physical capabilities of a person and should provide an effectiveness optimization and effectiveness improvement and includes in it general professional characteristic and demands, which profession makes on a person. As a part of job analysis, which contains description of demands to a personality, becomes psychogram. It contains description demand to psyche of a man of certain profession, content, first of all, a list of professionally important qualities.

Job analysis structure includes the following components.

Level name and specialization level.

Profession history.

Professional activity characteristics (prevailing kinds of activity, professional knowledge application area).

Job analysis (professionally-oriented necessities, socio-cultural qualities; professionally important qualities, such as orientation, competence; professional abilities; qualities, making difficulties of professional activity effectiveness)

Sanitary-hygienic working conditions (labour routine, neuropsychic tensity, medical contra-indications).

Occupational families.

Job analysis is scientifically norms and requirements to profession, professional activity kinds and specialist personality qualities, generalized standard model of successful specialist in given area.

One more model of specialist is his qualification characteristics, which serves as a standard of given profile specialist. Not only demands to personal characteristics of future specialist and to his work activity components are mentioned in it, but also fulfilment levels of corresponding labour processes. Qualification characteristics are created for description of qualified personnel training and serve as the basis of:

Degree of specialist's skills and their salary assignment;

Employee manual formulization, which contains a concrete list of job duties of employee with taking into account production organization peculiarities, labour and management, their rights and responsibility.

Qualification characteristics of each profession consist of three sections: "Job duties", "Must know" and "Demands to qualification". Let's mention general differences between job description and qualification characteristics. The first one describes socio-economical, sanitary-engineering, psychological and other peculiarities of profession, while in qualification characteristic considered not only profession or speciality and this profession bearer of certain qualification level.

Besides differences, in different approaches to plotting, there exist differences in aims of job description development and qualification characteristics. Job description development is made with an aim of formalized professional description, vocational selection updating, professional advisory service and professional adaptation, labour routine and labour conditions. Qualification characteristic is developed, generally to raise the efficiency of specialist's training planning, is targeted to assist a correct questions' of solving labour division and cooperation by means of clear definition of employees' job duties and qualification demands to them.

In our research the main entity-relationship model of specialist, on the base of which the educational model is build, we will consider job description. Created job description as a future specialist standard image, we define a graduate model, which is represented as qualification characteristics, and go to a stage of forming of training module shaping.

Considering training module as the heart of educational model, we highlight components, forming its inner structure:

Target component.

Since bearing structural component

Technological component (with which we achieve the goal)

Operational and activity component (how to organize study process).

Stimulating and motivational result component (how we will check, that we achieved the aim). 
Analytical component (efficiency analysis).

Correction component (recommendations to changing).

Final component.

Since bearing component of training, module becomes an education program, statutory document, which describes educational process conditions, content and educational abilities, with this it is a project of activity, which is fulfilled by its principal participants: a teacher and a student.

\subsection{An Algorithm of Comprehensive Educational Part (Educational Module)}

Aims and problems of education formulation.

Listeners' diagnostics

Educational necessities defining.

Finding of concrete functional problem (for what aim the listener needs knowledge, abilities, skills and qualities he should possess upon completion of education).

Basic training establishment through incoming control.

Comparison of a real competence level of a listener with demands of job description.

Finding of character and a volume of professional experience of people: all parameters of professional, daily, social activity, which will influence the character of organization and educational efficiency; possibilities of life experience usage of an adult as one of the education sources of itself or his colleagues.

Finding the level of achievements' motivation of listeners as a recipe for success in education.

Trainee contingent research.

Content design of cognitive part, qualified characteristics and logical structure of a course.

Educational material adaptation accordingly to the attainment level and psychological peculiarities of trainee.

Course schedule with concrete auditorium requirements consideration.

Educational block modules uncovering.

Connections between educational blocks uncovering.

Determination of educational block modules uncovering.

Varying educational programs development.

Awareness determination of educational material digestion by means of tests and assignments for submission system usage.

Andragogical educational methods usage.

Design of working part content on the basis of logical professional skills structure.

General educational and special educational abilities and skills uncovering. Their systematization.

Developing of motivation actions structure.

Selection of educational tasks system for performing actions system formation.

Formation of the corrective action system.

Formation of the controlling action system.

The choice of teaching means and methods according to the psycho-andragogical characteristics and life experiences of listeners.

Designing the content of creative projects (project method):

Choosing project theme.

Identification of adult groups to complete the project (at the level of knowledge, uneven-aged line-up) and the distribution of roles.

Identification of project completing stages (development strategy).

Formation of the system for controlling and evaluating the group and individual work performed.

Consideration of the teaching specific depending on the student's working mode: 
Table 1. Model of the adult education content and organization in the system of regional advanced education of profession type "man-machinery" (basis of information technologies)

\begin{tabular}{|c|c|}
\hline Stages & Actions \\
\hline \multirow{10}{*}{ Preparatory } & Analysis of the technological development of the region \\
\hline & $\begin{array}{l}\text { Analysis of the labour market: the requirement of employers, the required number of } \\
\text { vacancies }\end{array}$ \\
\hline & $\begin{array}{l}\text { Monitoring of the educational needs of people in the region for basic knowledge of } \\
\text { information technology }\end{array}$ \\
\hline & Analysis of the regional education market \\
\hline & Analysis of environmental factors: social and cultural differences \\
\hline & $\begin{array}{l}\text { Awareness of social and regional order for qualified profession of } \\
\text { "human-technology" type }\end{array}$ \\
\hline & Construction of professional situations bank \\
\hline & Allocation of roles and activities \\
\hline & Knowledge, abilities and skills to carry out activities \\
\hline & $\begin{array}{l}\text { Determination of personal qualities that are core of the information and technical } \\
\text { competency to perform activity types }\end{array}$ \\
\hline \multirow{3}{*}{$\begin{array}{l}\text { Building a model of the } \\
\text { graduate }\end{array}$} & Determination of requirements to the activity model and the model of personality \\
\hline & Building a job analysis as a passport of professional activity \\
\hline & Determination of qualifying characteristics (graduate model) \\
\hline \multirow{10}{*}{$\begin{array}{l}\text { Building } \\
\text { module }\end{array}$} & Emphasis on andragogical principles of training \\
\hline & Predicting the development of professional activity \\
\hline & Accounting capabilities of educational institutions \\
\hline & Formulation of goals and training objectives \\
\hline & Determination of diagnostic tools for students \\
\hline & $\begin{array}{l}\text { Construction of cognitive part content, of the qualification characteristics and logical } \\
\text { structure of the course on the basis of job analysis }\end{array}$ \\
\hline & $\begin{array}{l}\text { Construction of the operational part content based on the logical structure of } \\
\text { professional skills }\end{array}$ \\
\hline & Construction of the creative projects content (project-based training) \\
\hline & Consideration of the teaching specific depending on the student mode \\
\hline & Selection of systems thinking formation methods, practical skills and abilities \\
\hline \multirow{5}{*}{$\begin{array}{l}\text { Realization of } \\
\text { training module }\end{array}$} & Admission of knowledge requestor (level of knowledge, requirement, motivation) \\
\hline & Diagnosis of knowledge requestor \\
\hline & The learning process \\
\hline & Examination of the graduate \\
\hline & Justification that the graduate meets the qualification requirement \\
\hline \multirow{5}{*}{ Additional } & Admission of knowledge requestor (level of knowledge, requirement, motivation) \\
\hline & Diagnosis of knowledge requestor \\
\hline & The learning process \\
\hline & Examination of the graduate \\
\hline & Justification that the graduate meets the qualification requirement \\
\hline
\end{tabular}

Compilation of explanations and assignments to educational texts taking into account understanding barriers.

Formation of the independent assignment types system.

Formation of the control system.

Job analysis, being a profession model, and qualification characteristics, being a norm of planned professional and personal qualities of the graduate (a graduate model); create around themselves an integrated information environment-a model of the adult education content and organization. Let us describe the process of functioning 
of the integrated information environment of the adult education content and organization formation model.

The proposed model of the adult education content and organization for job training of "man-machinery" type (basis of information technologies) in the regional advanced education in expanded form is shown in Table 1.

Generalizing this scheme, we find that at the input of the adult education model in the system of additional education (MO), there come from the external environment the following: multiple objectives of the external environment $\mathrm{M}=\{\mathrm{Mj}\}$, forming factors $\mathrm{C}=\{\mathrm{Ci}\}$, multiple knowledge requestors $\mathrm{X}=\{\mathrm{Xt}\}$. The output of the system is two sets of final results: specialists of different levels $\mathrm{Y}=\{\mathrm{Yt}-\mathrm{r}\}$ intended to meet the demands of the external environment, and knowledge requestors who have not become experts $\mathrm{E}=\{\mathrm{Er}\}$. On the basis of these data, it should be noted that the quality of the specialist modelling system is manifested in two basic parameters: specialist's compliance with the external environment requirements; $r$ tending to zero (reduction in the number of requestors not formed into the specialists at the system output).

Data: $\mathrm{M}=\{\mathrm{Mj}\}$, where $\mathrm{j}$ is the number of the external environment objectives; $\mathrm{C}=\{\mathrm{Ci}\}$, where $\mathrm{i}$ is the number of external environment forming factors; $\mathrm{X}=\{\mathrm{Xt}\}$, where $\mathrm{t}$ is the number of knowledge requestors; $\mathrm{Y}=\{\mathrm{Yt}-\mathrm{r}\}$, where t-r is the number of specialists, and $r$ is the number of knowledge requestors who have not become specialists.

We have formed the following procedure of specialist projecting: $X-\underline{M O} \underline{(M, C)} \rightarrow Y \cup E$.

Provided that $\mathrm{E} \rightarrow \varnothing$ (i.e. $\mathrm{r} \rightarrow 0$ ), we can define the narrowing of our procedure to the system with maximum quality: $X-\underline{M O} \underline{(M, C)} \rightarrow Y$.

The expertise stage checks the compliance of the output parameter with the set objectives, namely with the professional and personal characteristics of the required specialization. The set of E, occurs at the stage of expertise, reflects the effectiveness of learning models. If the set of $\mathrm{E}$ is not empty, then the information model as a whole is functioning inefficiently, the model reveals a certain discrepancy with the set objectives or mismatch in the work of structural elements.

Expertise checks the professional and personal characteristics of the output parameter in a certain allowable range of efficiency [low coefficient of efficiency (LCE), ..., high coefficient of efficiency (HCE)]. Efficiency interval can be practically expressed in different ways, such as a permissible sum of scores received at the time of control measures passing. Thus, we obtain the following expression:

E (output _ parameter $) \in\left[\begin{array}{llll}L C E & , \ldots, & H C E\end{array}\right]$.

Expertise organizes the following creation procedure based on the input parameter (set of $\mathrm{X}$ ) of the two sets of output parameter ( $\mathrm{Y}$ and $\mathrm{E})$ to be checked at the efficiency interval [LCE, ..., HCE]:

S-the number of $\mathrm{X}$ set elements;

$\mathrm{X}$-knowledge requestors who passed the formation on the training module, but did not pass the professional competence expertise;

Y, E-empty sets;

PROCEDURE EXPERTISE;

FROM $\mathrm{i}=1$ TO $\mathrm{S}$ PERFORM

$\mathrm{IF} \mathrm{E}(\mathrm{Xi}) \in[\mathrm{LCE}, \ldots, \mathrm{HCE}] \mathrm{THEN} \mathrm{Y}=\mathrm{Y}+\mathrm{Xi}$ OTHERWISE E=E+ Xi;

END OF THE PROCEDURE.

Thus the range of [LCE, ..., HCE] indicates that the more results of the output parameter expertise tend to HCE, the more efficient is the functioning of a training module created on the information specialist model, while if the number of results equal to the HCE is also equal to the number of input parameter elements (set of X), then a training model can be considered as the most effective one.

Effectiveness of implementation of the adult education content and organization formation model correlates with the question of achieving those educational and training objectives, which are put in front of pedagogical science and educational system by the modern society, regional labour market and new socio-economic conditions. Thus, the effectiveness reveals the degree of conformity between the obtained results with the agreed objectives and tasks of the educational process represented by the trained graduate with the least investment of time, labour and health of teachers and students, funds (both from the side of a student and educational institution).

Work of any system is influenced by much interference. Sources of threats, forming a plurality of interference affecting the work of training model, can be divided into 3 groups. 
The human factor. This group of threats concerns the actions and behaviour of the person (teacher's incompetence, listener's non-comfortableness, conflict between teacher and students, conflicts between students, being late to class, inflated or deflated requirements put forward by the teacher, inadequate assessment of knowledge by teachers, etc.).

Technical factor. This threat group is connected with technical problems that interfere with the implementation of the educational process (power outage, technical equipment failures, problems with the software running, absence of chalk for boards, etc.).

Spontaneous factor. This threat group includes natural cataclysms, natural disasters and other force majeure events beyond the control of human activities.

Let us introduce the notations: $\mathrm{N}$-set of interference that can affect the work of the training model. Set of $\mathrm{N}$ is activated at the stage of training module implementation and expertise performance.

$|N|$-error of the system work (number of encountered interference).

$N=\left\{n_{i}\right\}$, where $\mathrm{i}=1 . . \mathrm{k}$

Let us determine the conditions for of adult training model efficiency:

Integration with regional labour market.

Predicting the professional needs.

$\mathrm{E} \rightarrow \varnothing$.

$\mathrm{N} \rightarrow \varnothing$.

Maximum number of $\mathrm{E}(\mathrm{X})$ corresponds to the HCE or is closely approaching it.

Factors affecting the correction of the adult training content and organization formation model can be defined as external and internal. The internal factors include the final expertise and the factors that make up the model. The external factors may include job analysis, adaptation and professional activity of graduates; analysis of indices of the competitor activity in the market of educational services (image, level of scientific and research work, quality control, quality of training, the level of teacher training).

\section{Discussion}

During the study, we concluded that the final model of adult training within the system of regional advanced education consists of the following stages:

Determination of the urgent needs of the regional socio-economic space in a new experience;

Adaptation of the new experience to opportunities of the regional advanced education system by converting it into knowledge and skills;

Organization of the educational environment (determination of forms and methods of adult training, selection of teaching staff, selection of technical and material base);

Determining the readiness of an adult for educational process;

Selection of alternative ways to get new experience based on previous experience, age and individual characteristics of adult learners;

Active obtaining of a new experiences, during which students must not only observe, but also intervene and facilitate the learning process;

Analysis of the experience in terms of its use in the present and the future;

Self-knowledge, where the preceding and obtained experience is considered by adults as an access to knowledge about themselves, contributing to the formation of new quality functions, expressed in recognition of the new social roles.

\section{Conclusion}

Having studied approaches of a large number of researchers concerning the problem of specialist model construction, we can conclude that the reference model of a specialist, in the case of the integration of its two main blocks: the activity model and the model of personality (professional qualities), becomes a reflection of the volume and structure of professional and socio-psychological qualities, knowledge, skills, collectively representing its generalized characteristic as a member of society. An example of such a model is job analysis, which includes the following components: psychogram (description of psychological norms, requirements to the 
activity and individuality of a specialist); professional and job requirements (description of the specific content of the specialist activity). Qualification characteristics, being a variant of the specialist model, are more focused not on the profession itself, but on the owner of this profession, and serve for professional training purposes, they also include qualification profile (combination of required types of professional activity and their level of qualification, qualification levels for payment).

Content selection and organization of training within the regional additional advanced adult education system can be represented as a formalized model and divided into five basic sequential stages:

First-monitoring the regional labour market, education market, educational needs at the regional level;

Second-modelling professional activity of a specialist with the allocation of the dominant activity types;

Third-allocation of qualities sets necessary for a successful career in the region, their classification on the knowledge, skills and personal qualities necessary for the performance of professional activities;

Fourth-educational content structuring;

Fifth-development of forms and andragogical training methods.

Thus, a model of the adult training content and organization formation is a project of accumulative system of knowledge, skills and abilities, and methods for their obtaining in the educational environment under the influence forming its goals and objectives. It should include the characteristics of the professional environment, the characteristics of activities, professional goals and personal characteristics needed to perform the activities and expertise of compliance with all internal parameters at the output of the model. Based on the reference model-the specialist's information model, representing a prototype of a specialist, training system can be built as a chain of technological process, through which a person with a certain initial properties is infiltrated and in the end there comes a person completely transformed, having learned the necessary set of society sociocultural abilities.

Our study allows stating that within the regional advanced education system, namely when forming the order for advanced training courses and retraining, a model of the adult training content and organization formation, which describes the basic requirements for the content and organization of the educational process, should:

be adequate to the ultimate goals and objectives of training;

include components that directly affect the social adjustment of the individual and entry into any professional activity;

have a structure that is easily diagnosed and monitored at all stages of the educational process;

provide not only the control for the process of becoming a professional, but also create opportunities for active interference in the educational process in order to perform correction and formation of the respective components;

include personal qualities, knowledge and skills that are necessary for solving tasks of the professional situation bank;

provide for the development of variable component, allowing students to master new technologies, demanded in the region;

ensure its continued development in accordance with the new realities, individual demands, social order;

make it possible to meet individual needs;

bear a predictive nature, that is, to focus not only on the initial stage of future professional activity, but also to cover the long-term professional growth, as well as possible changes in the profession.

In the future, the authors plan to develop their performed study through the creation of a regional advanced education centre for adults training and retraining.

\section{Acknowledgements}

We are grateful to the administration of the Sholom-Aleichem Priamursky State University (Birobidzhan, Russia) for assistance in the scientific research conducting.

\section{References}

Beckett, D. (2010). Adult Learning: Philosophical Issues. International Encyclopaedia of Education (Elsevier), 114-120. http://dx.doi.org/10.1016/B978-0-08-044894-7.00574-1

Bipp, T., \& van Dam, K. (2014). Extending hierarchical achievement motivation models: The role of motivational 
needs for achievement goals and academic performance. Personality and Individual Differences, 64, 157-162. http://dx.doi.org/10.1016/j.paid.2014.02.039

Bridewell, W., Sánchez, J. N., Langley, P., \& Billman, D. (2006). An interactive environment for the modelling and discovery of scientific knowledge. International Journal of Human-Computer Studies, 64(11), 1099-1114. http://dx.doi.org/10.1016/j.ijhcs.2006.06.006

Desjardins, R. (2010). Participation in Adult Learning. International Encyclopaedia of Education (Elsevier), 240-250. http://dx.doi.org/10.1016/B978-0-08-044894-7.00037-3

Dromantiene, L., \& Zemaitaityte, I. (2014). Challenges to Adult Education in Lithuania. Procedia-Social and Behavioral Sciences, 116, 4532-4536. http://dx.doi.org/10.1016/j.sbspro.2014.01.980

Gegenfurtner, A., \& Vauras, V. (2012). Age-related differences in the relation between motivation to learn and transfer of training in adult continuing education. Contemporary Educational Psychology, 37(1), 33-46. http://dx.doi.org/10.1016/j.cedpsych.2011.09.003

Green, A. E. (2009). Labor Markets, Regional. International Encyclopaedia of Human Geography (Elsevier), 85-90. http://dx.doi.org/10.1016/B978-008044910-4.00876-2

Guimarães, P., Alves, N., Cavaco, C., \& Marques, M. (2014). 3 Is Adult Education and Training Policy (1999-2011) in Portugal based on a Dilemma? The Critical Construction of the Employable Learner. Procedia-Social and Behavioral Sciences, 116, 4145-4149. http://dx.doi.org/10.1016/j.sbspro.2014.01.906

Gül, S. S., Kaya, H. E., Gül, H., \& Schweighofer-Brauer, A. (2013). Transcultural Biography Work in Adult Education: A Discussion on the Findings of a Pilot Study in Turkey. Procedia-Social and Behavioral Sciences, 93, 2028-2036. http://dx.doi.org/10.1016/j.sbspro.2013.10.160

Hava, H. T., \& Erturgut, R. (2010). Function of planning in adult education. Procedia-Social and Behavioral Sciences, 2(2), 3324-3328. http://dx.doi.org/10.1016/j.sbspro.2010.03.509

Leonelli, S., \& Ankeny, R. A. (2013). What makes a model organism? Endeavour, 37(4), 209-212. http://dx.doi.org/10.1016/j.endeavour.2013.06.001

McNamara, G., Joyce, P., \& O’Hara, J. (2010). Evaluation of Adult Education and Training Programs. International Encyclopaedia of Education (Elsevier), 548-554. http://dx.doi.org/10.1016/B978-0-08-044 894-7.01647-X

Merriam, S. B. (2010). Adult Learning. International Encyclopaedia of Education (Elsevier), 12-17. http://dx.doi.org/10.1016/B978-0-08-044894-7.00003-8

Rubenson, K. (2010). Adult Education Overview. International Encyclopaedia of Education (Elsevier), 1-11. http://dx.doi.org/10.1016/B978-0-08-044894-7.01723-1

Tett, L., \& Clair, R. St. (2010). Adult Literacy Education. International Encyclopaedia of Education (Elsevier), 107-112. http://dx.doi.org/10.1016/B978-0-08-044894-7.00019-1

Tuijnman, A. C. (2003). A "Nordic model" of adult education: What might be its defining parameters? International Journal of Educational Research, 39(3), 283-291. http://dx.doi.org/10.1016/j.ijer.2004.04.008

Von Hippel, P. T., \& Lynch, J. L. (2014). Why are educated adults slim-Causation or selection? Social Science \& Medicine, 105, 131-139. http://dx.doi.org/10.1016/j.socscimed.2014.01.004

Wallach, D., Makowski, D., Jones, J. W., \& Brun, F. (2014). Basics of Agricultural System Models. Working with Dynamic Crop Models. Academic Press, 3-44. http://dx.doi.org/10.1016/B978-0-12-397008-4.00001-0

Weiler, S. (2005). Regional labour market adjustment to structural shocks: An international comparison. The Social Science Journal, 42(3), 439-452. http://dx.doi.org/10.1016/j.soscij.2005.06.005

Zhang, Y. (2013). The development of users' mental models of Medline Plus in information searching. Library \& Information Science Research, 35(2), 159-170. http://dx.doi.org/10.1016/j.lisr.2012.11.004

\section{Copyrights}

Copyright for this article is retained by the author(s), with first publication rights granted to the journal.

This is an open-access article distributed under the terms and conditions of the Creative Commons Attribution license (http://creativecommons.org/licenses/by/3.0/). 